\title{
Isolation of Mycoplasma and Ureaplasma Species from Raccoon Dogs (Nyctereutes procyonoides viverrinus)
}

\author{
By YASUO KANAMOTO, ${ }^{1 *}$ HITOSHI KOTANI, ${ }^{2}$ MANABU OGATA ${ }^{3}$ AND \\ YOSHIYASU MATSUO ${ }^{4}$ \\ ${ }^{1}$ Division of Microbiology, Hiroshima Prefectural Institute of Public Health, Ujina-kanda 1-5-70, \\ Hiroshima, 734 Japan \\ 2 Imamichi Institute for Animal Reproduction, Dejima-mura, Ibaraki, 300-01 Japan \\ ${ }^{3}$ Department of Public Health, Azabu University School of Veterinary Medicine, Fuchinobe, \\ Kanagawa, 229 Japan \\ ${ }^{4}$ Department of Bacteriology, Hiroshima University School of Medicine, Kasumi 1-2-3,
} Hiroshima, 734 Japan

(Received 9 December 1982; revised 10 February 1983)

\begin{abstract}
Mycoplasma spp. were isolated from five wild raccoon dogs ( $N y$ ctereutes procyonoides viverrinus). On the basis of biochemical properties and serological tests, nine isolates were identified as Mycoplasma edwardii and four were similar to a possibly new Mycoplasma sp. represented by strain LM2 which is negative for both glucose fermentation and arginine hydrolysis. In addition, ureaplasmas were detected from these animals. Ureaplasmas were compared serologically with ureaplasma strains isolated from human, monkey, cattle, goat, sheep, cat, chicken and dog and cross-reacted with one of four serological groups of canine ureaplasmas.
\end{abstract}

\section{INTRODUCTION}

With regard to ecological studies on the distribution of mycoplasmas in various species of animals, a large number of reports have been published of mycoplasmas in domestic mammals and domestic fowls, but few surveys of these organisms have been made in wild animals.

Mycoplasmas have been isolated from wild cat (Hill, 1972), chamois (Nicolet \& Freund, 1975), ground squirrel (Langford, 1977), hedgehog (Tan et al., 1971), non-human primates (Barile, 1973), elephant (Clark et al., 1980) and several species of wild birds (Koshimizu et al., 1978; Shimizu et al., 1979).

We have reported previously the isolation of mycoplasmas from wild raccoon dog (Nyctereutes procyonoides viverrinus), fox (Vulpes vulpes japonica) and Japanese badger (Meles meles anakuma) (Kanamoto et al., 1981). This communication provides a more detailed assessment of the results of mycoplasmal isolation from raccoon dogs.

\section{METHODS}

Animals. Five raccoon dogs (Nyctereutes procyonoides viverrinus), four females and one male, caught in the wild from March to April 1981, were used for isolation of mycoplasmas. All of these animals were adult and appeared to be healthy.

Media. T-broth and T-agar (Ogata et al., 1979) were used for the isolation of ureaplasmas. The composition of the medium (PPLO-broth, PPLO-agar) used for isolation of mycoplasmas has been described previously (Kanamoto et al., 1981).

Isolation. The oral cavity, nasal cavity, external ear, rectum, vagina and prepuce of these animals were wiped with sterilized cotton swabs and the swabs thus obtained were immersed in test tubes containing 2 ml tryptic soy

Abbreviation: GI, Growth inhibition. 
Table 1. Strains of mycoplasma species or serovars used in comparative studies

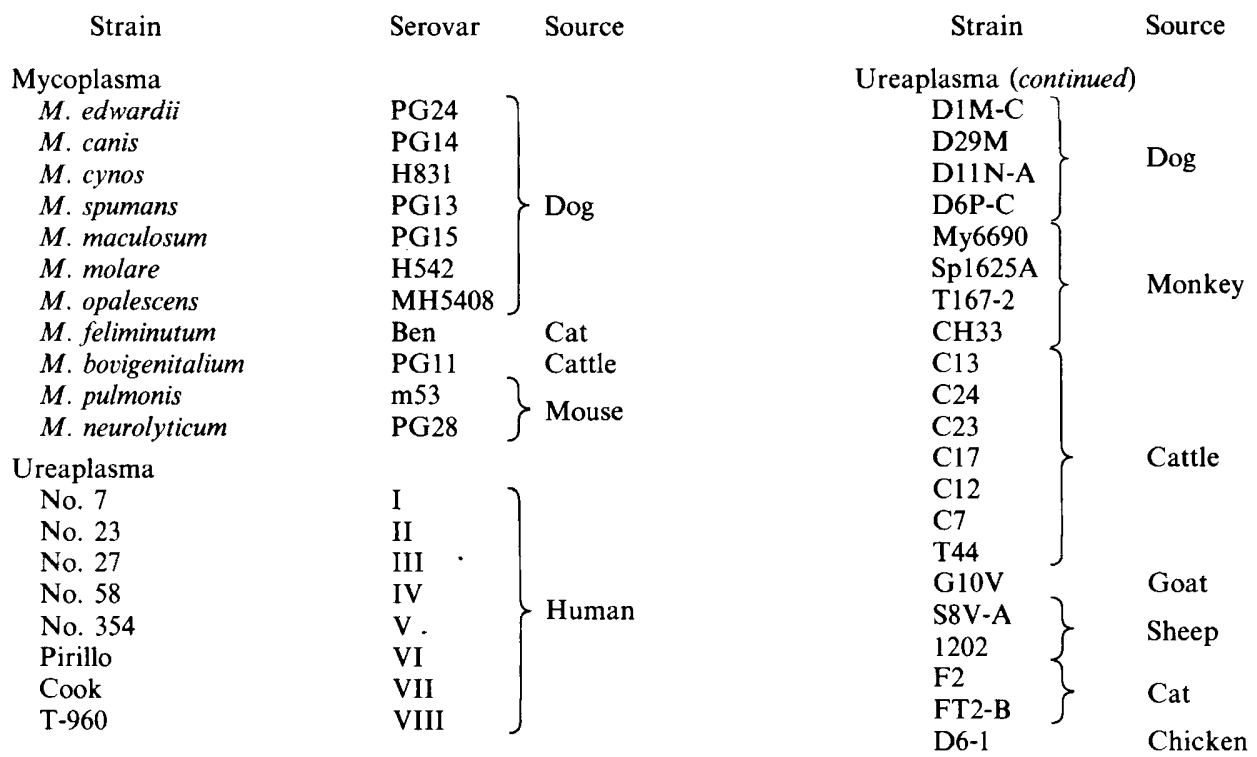

broth (BBL) supplemented with horse serum. The specimens were placed in a low temperature preservation box and transported to the laboratory, Hiroshima Prefectural Institute of Public Health, Japan. The specimen (1 ml) was inoculated into test tubes containing $1.8 \mathrm{ml} \mathrm{T}$-broth and PPLO-broth, respectively, and 10 -fold dilutions to $10^{-5}$ were made. These were incubated at $37^{\circ} \mathrm{C}$ for a week. The cultures showing colour changes were subcultured on T-agar and PPLO-agar. Duplicate cultures were incubated at $37^{\circ} \mathrm{C}$ in an atmosphere of aerobic condition and of $10 \% \mathrm{CO}_{2}-90 \% \mathrm{~N}_{2}(\mathrm{v} / \mathrm{v})$.

Antisera. These were prepared as described by Ogata et al. (1979).

Reference strains. Mycoplasma reference strains used for biochemical and serological tests are shown in Table 1. In addition, mycoplasma strain LM2 isolated previously from a raccoon dog by the present authors (Kanamoto et al., 1981) was included in the present study.

Ureaplasma reference strains (Table 1) used for serological tests were of human, monkey, cattle, goat, sheep, cat, chicken and canine origins, described previously (Kotani et al., 1980).

Biochemical and serological tests. Biochemical tests were carried out by the methods reported by Aluotto et al. (1970). The serological test used for mycoplasmas was the growth inhibition (GI) test (Clyde, 1964), and for ureaplasmas was the GI test (Ogata et al., 1979).

\section{RESULTS}

The number of isolates of mycoplasmas from raccoon dogs is shown in Table 2. Nineteen isolates were cloned three times or more (Koshimizu \& Magaribuchi, 1978) and examined further. Nine of the isolates were identified as Mycoplasma edwardii. They had the same biochemical properties, i.e. they were digitonin sensitive, did not reduce tetrazolium chloride, fermented glucose but did not hydrolyse arginine or possess urease activity. These strains were finally identified as $M$. edwardii by the GI test.

Four of the isolates appeared similar to a previously isolated but unnamed Mycoplasma sp. strain LM2 (Kanamoto et al., 1981). These strains cross reacted with LM2 antisera in the GI test. They also failed to ferment glucose, hydrolyse arginine or urea, to reduce tetrazolium and produce film and spots. All were inhibited by digitonin.

Six of the isolates were identified as ureaplasmas. They were found to cross react in the GI test with antisera to ureaplasma strain D1M-C, one of the representative serological types from dogs. They did not react with antisera to any of the other ureaplasma strains listed in Table 1 . 
Table 2. Isolation of mycoplasmas from raccoon dogs

The results are expressed as (No. of specimens positive for mycoplasma or ureaplasma)/(No. of specimens examined). Each specimen was from a different raccoon dog.

\begin{tabular}{|c|c|c|}
\hline Site tested & Mycoplasma & Ureaplasma \\
\hline Oral cavity & $5 / 5$ & $5 / 5$ \\
\hline Nasal cavity & $2 / 5$ & $4 / 5$ \\
\hline External ear & $0 / 5$ & $0 / 5$ \\
\hline Rectum & $3 / 5$ & $1 / 5$ \\
\hline Vagina & $0 / 4$ & $0 / 4$ \\
\hline Prepuce & $0 / 1$ & $0 / 1$ \\
\hline Total & $10 / 25$ & $10 / 25$ \\
\hline
\end{tabular}

\section{DISCUSSION}

Since ureaplasmas were first isolated from the urinary tract of man by Shepard (1954), these micro-organisms have been isolated from many mammals such as cattle (Taylor-Robinson et al., 1967), dog (Taylor-Robinson et al., 1971), cat (Tan \& Markham, 1971), monkey (Brown et al., 1976), sheep (Livingston \& Gauer, 1975), goat (Gourlay et al., 1973), mink (Friis et al., 1980) and pig (Stipkovits et al., 1978). Most of these animals were domestic animals or pets, and there have been no reports of ureaplasmas in wild animals.

Attempts were made in the present study to isolate mycoplasmas from wild raccoon dogs. Ureaplasma spp. and Mycoplasma edwardii were isolated and identified for the first time from this source. Ureaplasma strains isolated cross-reacted with antiserum to one of the four serological groups originated from dogs. Nine mycoplasma strains were identified as $M$. edwardii whose host was originally dogs (Rosendal, 1975).

Four other isolates had properties similar to strain LM2 which had been isolated previously from a raccoon dog. These strains seem to be a new species of mycoplasma, and identification is under investigation.

We wish to thank Mr Y. Fukumoto, Asa Zoological Park, for allowing us to obtain samples from the raccoon dogs.

\section{REFERENCES}

Aluotto, B. B., Wittler, R. G., Williams, C. O. \& FABER, J. E. (1970). Standardized bacteriologic techniques for the characterization of Mycoplasma species. International Journal of Systematic Bacteriology 20, 35-58.

BARILE, M. F. (1973). Mycoplasmal flora of simians. Journal of Infectious Diseases 127, S17-S20.

Brown, W. J., JACOB, N. F., JR, ARUM, E. S. \& Arko, R. J. (1976). T-strain mycoplasma in the chimpanzee. Laboratory Animal Science 26, 81-83.

Clark, H. W., Laughlin, D. C., Bailey, J. S. \& BRown, T. M. (1980). Mycoplasma species and arthritis in captive elephants. Journal of Zoo Animal Medicine 11, 3-15.

Clyde, W. A., JR (1964). Mycoplasma species identification based upon growth inhibition by specific antisera. Journal of Immunology 92, 958-965.

Frils, N. F., Pedersen, K. B. \& Bloch, B. (1980). Ureaplasma isolated from the respiratory tract of mink. Acta veterinaria scandinavica 21, 134-136.

Gourlay, R. N., Brownlie, J. \& Howard, C. J, (1973). Isolation of T-mycoplasmas from goats, and the production of subclinical mastitis in goats by the intramammary inoculation of human T-mycoplasmas. Journal of General Microbiology 76, 251-254.
HILl, A. (1972). The isolation of Mycoplasma arginini from captive wild cats. Veterinary Record 91, 224225.

Kanamoto, Y., Kotani, H., Ogata, M. \& Fukumoto, Y. (1981). Isolation of mycoplasmas from raccoon $\operatorname{dog}$ (Nyctereutes procyonoides viverrinus), fox (Vulpes vulpes japonica), Japanese badger (Meles meles anakuma). Japanese Journal of Veterinary Science 43, 267-271.

Koshimizu, K. \& Magaribuchi, T. (1978). Biological and serological characterization of ureaplasmas isolated from domestic fowls and red jungle fowls. Japanese Journal of Veterinary Science 40, 719-727.

Koshimizu, K., Magaribuchi, T., Tanabe, K. \& KONO, N. (1978). Isolation and characterization of mycoplasmas from Gallinaceous birds. Japanese Journal of Veterinary Science 40, 445-449.

Kotani, H., Nagatomo, H. \& OGata, M. (1980). Isolation and serological comparison of ureaplasmas from goats and sheep. Japanese Journal of Veterinary Science 42, 31-40.

LANGFORD, E. V. (1977). The recovery of a mycoplasma from Citellus richardsonii richardsonii (ground squirrel). Canadian Journal of Comparative Medicine 41, 224-225. 
Livingston, C. W., JR \& Gauer, B. B. (1975). Isolation of T-strain mycoplasma from sheep and goats in Texas. American Journal of Veterinary Research 36, 313-314.

Nicolet, J. \& Freundt, E. A. (1975). Isolation of Mycoplasma conjunctivae from chamois and sheep affected with keratoconjunctivitis. Zentralblatt für Veterinärmedizin B22, 302-307.

Ogata, M., Kotani, H. \& Yamamoto, K. (1979). Serological comparison of bovine ureaplasmas. Japanese Journal of Veterinary Science 41, 629-637.

Rosendal, S. (1975). Canine mycoplasmas: cultural and biochemical studies of type and preference strains. Acta pathologica et microbiologica scandinavica B83, 463-470.

SHEPARD, M. C. (1954). The recovery of pleuropneumonia-like organisms from Negro men with and without non-gonococcal urethritis. American Journal of Syphilis, Gonorrhea and Venereal Diseases 38, 113124.

Shimizu, T., Numano, K. \& Uchida, K. (1979). Isolation and identification of mycoplasmas from various birds: an ecological study. Japanese Journal of Veterinary Science 41, 273-282.

Stipkovits, L., Rashwan, A., Takacs, J. \& Lapis, K. (1978). Occurrence of ureaplasmas in swine semen. Zentralblatt für Veterinärmedizin. B25, 605-608.

TAN, R. J. S. \& MARKhaM, J. G. (1971). Feline T-strain mycoplasmas. Japanese Journal of Experimental Medicine 41, 247-248.

Tan, R. J. S., Davey, G. P. \& Smith, J. M. B. (1971). A strain of Mycoplasma from the short-eared European hedgehog (Erinaceus europaeus). Research in Veterinary Science 12, 390-391.

Taylor-Robinson, D., Haig, D. A. \& Williams, M. H. (1967). Bovine T-strain mycoplasma. Annals of the New York Academy of Sciences 143, 517-518.

Taylor-Robinson, D., Martin-Bourgon, C., Watanabe, T. \& ADDEY, J. P. (1971). Isolation of T-mycoplasma from dogs and squirrel monkeys: biological and serological comparison with those isolated from man and cattle. Journal of General Microbiology 68, 97-107. 